\title{
ACOMPANHAMENTO E CONTROLE FINANCEIRO INFORMATIZADO DAS OPERAÇÕES DE VENDAS EM EMPRESA MINEIRA DE MATERIAL DE CONSTRUÇÃO DE PEQUENO PORTE
}

\author{
MONITORING AND CONTROL OF COMPUTERIZED \\ FINANCIAL SALES OPERATIONS IN MINING COMPANY \\ OF SMALL CONSTRUCTION MATERIAL PORTE
}

Recebido: 28/03/2016 - Aprovado: 07/06/2016 - Publicado: 30/06/2016

Processo de Avaliação: Double Blind Review

\author{
Vanessa Ramos Silva ${ }^{1}$ \\ Mestre em Ciências Contábeis pela Universidade Federal de Uberlândia (UFU) \\ Universidade Federal de Uberlândia (UFU) \\ vanessaramossilva@hotmail.com
}

\section{Graciela Dias Coelho Jones}

Docente da Faculdade de Ciências Contábeis (FACIC) da Universidade Federal de Uberlândia (UFU).

Universidade Federal de Uberlândia (UFU)

graciela@facic.ufu.br

RESUMO: - O objetivo deste trabalho é analisar o processo de acompanhamento e controle financeiro informatizado das operações de vendas em uma empresa comercial de material de construção. Adicionalmente, propõe-se a adoção do planejamento orçamentário de vendas como instrumento de gestão. Para tanto, foi desenvolvido um estudo de caso em uma empresa de material de construção mineira de pequeno porte. $\mathrm{O}$ estudo discute as vantagens do processo de acompanhamento e controle financeiro informatizado das operações de vendas, por meio da apresentação de telas do Sistema de Informação utilizado pela empresa e as opções disponibilizadas aos usuários para o referido processo, desde o cadastro de clientes até o recebimento. Considerando-se que a empresa não elabora o Planejamento Orçamentário anual, tão importante instrumento de gestão, o presente trabalho propõe a adoção do Orçamento de Vendas, e apresenta as vantagens da sua implantação. Entende-se, contudo, a

\footnotetext{
${ }^{1}$ Autor para correspondência: Universidade Federal de Uberlândia. Av. João Naves de Ávila, 2121 - Bloco 3P - Sala 300 - $3^{\circ}$ andar Prédio da Reitoria da UFU- Campus Santa Mônica - CEP 38400-902- Brasil
} 
importância em se estender a implantação do orçamento as demais peças orçamentárias. Como resultado obteve-se que são inúmeros os benefícios do Sistema de Informação para o gerenciamento financeiro das operações de vendas. O Orçamento de Vendas apresenta-se como alternativa para o acompanhamento da execução e controle das operações de vendas e para o processo de tomada de decisão.

Palavras-chave: Planejamento; Controle financeiro; Sistema de informação; Orçamento de vendas.

ABSTRACT: The objective of this study is to analyze the process of monitoring and computerized financial control of sales operations at a commercial building material. Additionally, it is proposed to adopt the budget planning sales management tool. To this end, we developed a case study on a construction material company small mineira. The study discusses the advantages of the process of monitoring and computerized financial control of sales operations, through the presentation of screens Information System used by the company and the options available to users for that process, from customer master until receipt. Considering that the company does not prepare the annual Budget Planning as important management tool, this paper proposes the adoption of the Budget, Sales, and presents the advantages of its implementation. It is understood, however, the importance of extending the implementation of the budget other parts budget. As a result it was found that there are numerous benefits of the Information System for the financial management of sales operations. The Budget Sales presents itself as an alternative to monitoring the implementation and control of sales operations and process of decision making.

Keywords: Planning; Financial control; Information system; Sales budget. 


\section{INTRODUÇÃO}

Na condição atual, de grande concorrência do mercado, planos estratégicos adotados de forma correta e no tempo certo, são fatores determinantes para sobrevivência das empresas. Independente do porte da empresa, planejar e controlar resultados representam ações necessárias para atuação no mercado, visando antecipar oportunidades e ameaças. Uma atenção especial precisa ser dispensada às micro e pequenas empresas, no Brasil. As taxas de mortalidade de empresas com até dois anos, para as empresas nascidas em 2007, foi de 21,8\% no Sudeste. Em 2007, foram constituídas 15.572 empresas de comércio varejista de ferragens, madeira e materiais de construção no Brasil, de acordo com dados do Sebrae (2013), e a taxa de sobrevivência em dois anos foi de $83 \%$.

O volume de vendas torma-se elemento fundamental para identificação do nível de atividades e do porte da empresa, e consequentemente deve ser alvo de permanente acompanhamento e controle. Estimativas de vendas possibilitam antecipação de informações sobre o ingresso de recursos na empresa, nível de produção necessários para atendimento da demanda, previsão de fontes de recursos, caso seja necessário.

O acompanhamento e controle das operações de vendas auxilia o processo de gestão e aumenta as possibilidades da permanência das empresas no mercado. Neste contexto, a questão de pesquisa que norteou o estudo foi: Quais são as contribuições do processo de gerenciamento informatizado no acompanhamento e controle financeiro das operações de vendas e do Orçamento de Vendas em empresas comerciais de material de construção?

O objetivo geral do estudo, portanto, é analisar o processo de acompanhamento e controle financeiro informatizado das operações de vendas em uma empresa comercial de material de construção. Adicionalmente, propõe-se a adoção do planejamento orçamentário de vendas como instrumento de gestão. Para tanto, foi desenvolvido um estudo de caso em uma empresa de material de construção de pequeno porte localizada em Minas Gerais.

O presente estudo não pretende estender a discussão sobre o processo orçamentário como um todo, mas abordar especificamente a questão da proposição do Orçamento de Vendas, fundamental para a determinação do volume de atividades da empresa, visando apresentar alternativa adequada para o gerenciamento das operações de vendas. Sanvicente e Santos (2000) entendem que o orçamento de vendas nada mais é do que um plano de vendas futuras, para um determinado período, e tem como função principal projetar o nível de 
atividades futuras da empresa. Entende-se, contudo, a importância de se estender a implantação da proposta às demais peças orçamentárias.

Assim, justifica-se o estudo pela contribuição que ele pode trazer para futuras pesquisas sobre a temática da utilização do SI no gerenciamento das operações de vendas e sobre a importância do Orçamento de Vendas para empresas. O Orçamento é um dos temas que mais motivam pesquisas em periódicos internacionais e é uma das temáticas centrais da contabilidade gerencial (LUFT; SHIELDS, 2003). Leite et al. (2008, p.70), apontam que "o tema 'orçamento' é muito pouco investigado entre a produção científica mais expressiva em Instituições de Ensino Superior". Os temas de contabilidade gerencial mais valorizados e eleitos como mais relevantes pela maioria dos respondentes da pesquisa de Frezatti et al (2008) foram os temas relativos aos sistemas de informações gerenciais e relatórios gerenciais $(68,3 \%)$, planejamento estratégico formal $(41,5 \%)$, orçamento $(22 \%)$, avaliação de desempenho e gestão estratégica de custos $(19,5 \%)$.

Atualmente, ainda são poucos os estudos sobre as causas das empresas de menor porte. Como contribuição prática tem-se que o estudo sobre o acompanhamento e controle financeiro informatizado das operações de vendas pode auxiliar empresas de pequeno porte do setor e de outros setores que estejam buscando informações sobre os benefícios e vantagens da implantação de SI e do Orçamento de Vendas como instrumentos de gestão.

Além dessa introdução, o artigo divide-se em mais três tópicos. No próximo, apresenta-se o referencial teórico para embasar o desenvolvimento do trabalho. O terceiro tópico consiste em abordar os aspectos metodológicos do estudo. $\mathrm{O}$ quarto contempla os resultados do estudo realizado. Por fim, a última parte apresenta as considerações finais.

\section{REFERENCIAL TEÓRICO}

\subsection{A INTERDEPÊNDENCIA ENTRE PLANEJAMENTO E CONTROLE}

Planejar "é estabelecer com antecedência as ações a serem executadas, estimar os recursos a serem empregados e definir as correspondentes atribuições de responsabilidades em relação a um período futuro determinado, para que sejam alcançados satisfatoriamente os objetivos fixados para a empresa" (SANVICENTE; SANTOS, 2000, p. 16). O planejamento e controle, conforme Frezatti (2008), podem assumir diferentes perfis, quando restritos às atividades de planejamento ou de controle. Complementando, o mesmo autor reforça que 
quem não planeja não pode afirmar que controla, já que não consegue indicar onde quer chegar (FREZATTI, 2008).

Conforme Migliato (2004, p. 31) "entende-se por planejamento a atividade de se definir um futuro desejado e de se estabelecer os meios pelos quais este futuro será alcançado". Planejamento significa o desenvolvimento de um programa para a realização de objetivos e metas organizacionais, e envolve escolhas de curso de ação, a decisão antecipada do que deve ser feito, a determinação de quando e como a ação deve ser executada (TERENCE, 2002).

O planejamento é a chave para uma boa gestão, seja para pequenas empresas familiares, grandes corporações, agências governamentais e organizações sem fins lucrativos, ou simplesmente para os indivíduos, ou para a vida pessoal (HORNGREN; SUNDEM; STRATON, 2004).

Welsch (1983) define o controle como sendo simplesmente a ação necessária para verificar se os objetivos, planos, políticas e padrões estão sendo obedecidos. Já o planejamento e controle é "um enfoque sistemático e formal à execução das responsabilidades de planejamento, coordenação e controle da administração" (WELSCH, 1983, p. 21). O planejamento e controle precisam ser aplicados para a empresa como um todo, porém para cada área estratégias diferentes são desenvolvidas.

\subsection{A IMPORTÂNCIA DO PLANEJAMENTO ORÇAMENTÁRIO DE VENDAS}

O orçamento é um plano detalhado da aquisição e do uso dos recursos financeiros ou de outra natureza, durante um período especificado. Ele representa um plano para o futuro, expresso em termos quantitativos (CAVALCANTE, 2010). O sistema de orçamento é um instrumento de planejamento e controle de resultados econômicos e financeiros. É um modelo de mensuração que avalia e demonstra, por meio de projeções, os desempenhos econômicofinanceiros da empresa, bem como das unidades que a compõem (HOJI, 2007).

"O orçamento tem como princípio fundamental o planejamento e o controle do resultado, através do planejamento formal, da coordenação efetiva e do controle dinâmico das operações da empresa" (BORNIA; LUNKES, 2007, p. 39).

Atkinson et al, (2000, p. 465) destaca:

[...] o orçamento é uma ferramenta que força a coordenação das atividades da organização e ajuda a identificar problemas de coordenação. [...] Se o planejamento 
orçamentário indica que o potencial de vendas da empresa excede seu potencial de produção, ela pode desenvolver um plano para aumentar sua capacidade ou reduzir as vendas planejadas.

As vendas representam a fonte básica de entrada de recursos monetários, os investimentos adicionais em ativo imobilizado, o volume de despesas a ser planejado, as necessidades de mão-de-obra, o nível de produção e outros aspectos operacionais importantes dependem do orçamento de vendas (WELSCH, 1983).

O mesmo autor menciona que o plano de vendas é o alicerce do planejamento periódico numa empresa, pois praticamente todo o restante do planejamento da empresa baseia-se nas estimativas de vendas (WELSCH, 1983).

Em relação à previsão de vendas tem-se que o nível de operação que se espera é fixado pela estimativa básica do volume de vendas previsto no período (PEREZ JR.; PESTANA; FRANCO, 1997). Horngren, Sundem e Stratton (2004) complementam que a "previsão de vendas" é uma predição, ou seja, um prognóstico, do volume de vendas sob um determinado conjunto de condições. A previsão de vendas pode ajudar a companhia a antecipar duas situações que demandam decisões adicionais por parte do gerente de operações, como por exemplo os cenários em que a demanda real ultrapassa a capacidade planejada ou em que capacidade planejada ultrapassa a demanda real (FURRIER; SERRALVO, 2008). De acordo com Mentzer e Bienstock (1998), a previsão de vendas é uma projeção futura da demanda esperada, dadas as condições ambientais.

Sanvicente e Santos (2000, p. 43) mencionam que "todos os demais orçamentos parciais são desenvolvidos em função do orçamento de vendas [...].” Moreira (2002, p. 60) complementa "o orçamento de vendas é a peça básica de elaboração do orçamento, condicionando todo o processo."

A importância do uso da ferramenta orçamentária é destacada por Horngren (2000, p. 125): "os sistemas de orçamentos fazem com que os administradores olhem para frente, o que os coloca numa melhor posição para aproveitar oportunidades.”

Um dos fatores determinantes para a competitividade das empresas consiste num adequado acompanhamento da execução e controle das operações de vendas. O departamento de vendas tem destaque nas empresas, conforme Las Casas (2004), por representar um instrumento de comunicação com o mercado que a empresa atua, assim para a empresa material de construção não é diferente. 
O trabalho de Camargo e Giraldi (2007) teve o objetivo da construção de um modelo de previsão de vendas baseado na metodologia de Box-Jenkins para prever as necessidades futuras do mercado consumidor e desta forma, auxiliar o gestor na tomada de decisão, utilizando como variáveis o volume de vendas de três produtos. Os resultados foram de grande importância para a empresa estudada que poderá aumentar a sua capacidade produtiva de acordo com as necessidades das demandas do mercado.

O estudo de Jones, Ribeiro e Rogers (2010) apresentou um modelo de acompanhamento e controle do orçamento de vendas, por meio de planilhas gerenciais, para instrumentalizar o gerenciamento das operações de vendas. $\mathrm{O}$ modelo proposto disponibiliza informações para o conhecimento antecipado da posição das vendas acumuladas, num intervalo de dias estabelecido pelo gestor, antes da finalização do mês, possibilitando que providências sejam tomadas pelos gestores, para melhorar a performance das vendas da empresa no referido mês, permitindo uma maior chance dela atingir o orçamento de vendas.

\subsection{CONTROLE FINANCEIRO E GESTÃO DE RECEBÍVEIS}

O planejamento e controle financeiro podem ser definidos, em termos amplos, como "um enfoque sistemático e formal à execução das responsabilidades de planejamento, coordenação e controle da administração (WELSCH, 1983, p. 21). Tão importante quanto o Orçamento de Vendas é o acompanhamento e controle financeiro da sua execução, que tem como uma de suas etapas a gestão de recebíveis. Para Lemes Júnior, Rigo e Cherobim (2002), o risco de crédito representa para a política de crédito a possibilidade de não recebimento do todo ou de parte da venda a crédito realizada, e sempre haverá risco de perdas com os devedores duvidosos.

Para Assaf e Silva (2002), o crédito é uma troca de bens presentes por bens futuros e uma empresa ao conceder crédito troca produtos por uma promessa de pagamento futuro. Portanto, o crédito é um valioso instrumento para as organizações, pois possibilita um aumento de vendas (BELLÓRIO; RIBEIRO; ROGERS, 2005).

Ao elaborar a ficha cadastral, deve-se procurar ser o mais claro possível, escolhendo bem os termos que irão dar os nomes aos campos que irão ser preenchidos (SECURATO, 2002). Nas empresas que utilizam as propostas eletrônicas, ou seja, sistemas informatizados que registram os dados da ficha cadastral, a ordem de distribuição nos campos na tela do computador deve seguir uma ordem mais próxima possível da ordem apresentada na ficha 
cadastral em papel, para facilitar o trabalho de digitação. A situação do cliente, mesmo daqueles antigos e tradicionais, deve ser constantemente monitorada e revista, quanto aos aspectos de pontualidade, capacidade de pagamento e condição financeira (HOJI, 2007).

De acordo com Securato (2002), a concessão de crédito é avaliada através de análise da ficha cadastral do cliente, considerando um sistema de pontuação, visando mensurar parâmetros definidos e atribuir pesos conforme a relevância de cada informação e a partir da pontuação obtida, o crédito será concedido ou analisado de acordo com a política de crédito da empresa.

Para Medeiros, Brito e Araujo (2008), as políticas de crédito e cobrança precisam estar em harmonia com o mercado e com os negócios da empresa; elas são relevantes e precisam ser definidas de forma clara.

Assaf (2008) afirma que o monitoramento das operações de crédito é de grande importância, além de ser uma atividade permanente na gestão financeira da empresa, levantando informações relevantes, como apurar o nível de atraso com que os clientes estão pagando; identificar a pontualidade com que os clientes saldam seus compromissos e entender as razões que determinam a variação na carteira de valores a receber. Os sistemas informatizados oferecem ferramentas que podem auxiliar a gestão de recebíveis pelos gestores.

\subsection{SISTEMA DE INFORMAÇÃO}

O’Brien (2004, p. 6) define sistema de informação como "um conjunto organizado de pessoas, hardware, software, redes de comunicações e recursos de dados que coleta, transforma e dissemina informações em uma organização."

\footnotetext{
Um sistema de informação pode ser definido como um conjunto de componentes inter-relacionados que coleta (ou recupera), processa, armazena e distribui informações destinadas a apoiar a tomada de decisões, a coordenação e o controle de uma organização. Além de dar suporte à tomada de decisões, à coordenação e ao controle, esses sistemas também auxiliam os gerentes e trabalhadores a analisar problemas, visualizar assuntos complexos e criar novos produtos (Laudon \& Laudon, 2004, p. 7).
}

Os sistemas de informação, segundo Machado (2002), possuem como característica a integração entre os diversos elementos que o compõem e a interação com os outros sistemas da organização empresarial. As empresas têm partilhado os sistemas de informação contábil 
em duas grandes áreas: (a) a área societária e fiscal, denominada de escrituração; e (b) a área gerencial, denominada de planejamento e controle (PADOVEZE, 2000). Para serem eficazes os gerentes precisam produzir resultados e estes decorrem de suas próprias ações. A qualidade das ações, entretanto, depende do processo de tomada de decisões dos gerentes, o qual, por sua vez, requer o suporte de um adequado sistema de informações (NAKAGAWA, 1993).

Quando a empresa disponibiliza, por intermédio do Sistema de Informação, informações devidamente ordenadas e organizadas na forma de relatórios estruturados, os gestores contam com maior subsídio, para o processo de tomada de decisão (JONES; RIBEIRO; ROGERS, 2007). O processo decisório para Catelli (2001), envolve a escolha do curso de ação mais apropriado para a implementação das decisões estratégicas. Assim, a informação é o fluido vital de qualquer sistema e a responsabilidade pelo desempenho de um sistema de informações adequado é a principal preocupação de qualquer administrador.

Vários subsídios são utilizados para o planejamento e controle, um deles é a adoção de instrumentos que auxiliem na obtenção de informações gerenciais confiáveis. Guerreiro (1992) expressa que os gestores têm grande dependência do recurso informação, que se constitui de maneira fundamental no processo de gestão. Os Sistemas de Informação (SI) tem apresentado opções específicas para diversos segmentos de mercados. Entre os sistemas disponíveis para gestão integrada tem-se o ERP - Enterprise Resource Planning que "é um sistema integrado, que possibilita um fluxo de informações único, contínuo e consistente por toda a empresa, sob uma única base de dados" (PADILHA; MARINS, 2004, p. 104).

No próximo tópico são apresentados os aspectos metodológicos do estudo desenvolvido.

\section{ASPECTOS METODOLÓGICOS}

A seguir, o Quadro 1 apresenta o resumo dos aspectos metodológicos adotados para o desenvolvimento do presente estudo. 


\begin{tabular}{|l|l|}
\hline \multirow{2}{*}{ plassificação da } & $\begin{array}{l}\text { Pesquisa Exploratória. Com esta pesquisa "busca-se conhecer com } \\
\text { maior profundidade o assunto de modo a torná-lo mais claro ou } \\
\text { construir questões importantes para a condução da pesquisa" (RAUPP; } \\
\text { BEUREN, 2006, p. 80). }\end{array}$ \\
\hline Análise & $\begin{array}{l}\text { Qualitativa. Para Raupp e Beuren (2006, p. 92) "na pesquisa } \\
\text { qualitativa concebem-se análises mais profundas em relação ao } \\
\text { fenômeno que está sendo estudado." }\end{array}$ \\
\hline $\begin{array}{l}\text { Documental. Marconi e Lakatos (2006) destacam que nesta coleta de } \\
\text { dados a fonte dos dados consiste em documentos primários ou } \\
\text { secundários. } \\
\text { Entrevista. De acordo com Gil (2002, p. 115) "a entrevista é aplicável a } \\
\text { um número maior de pessoas [...] possibilita o auxílio ao entrevistado } \\
\text { coleta de dados }\end{array}$ & $\begin{array}{l}\text { com dificuldade para responder, bem como a análise do seu } \\
\text { comportamento não verbal. } \\
\text { Estudo de caso. Segundo Yin (2001, p. 19) "é apenas uma das muitas } \\
\text { maneiras de se fazer pesquisa em ciências sociais." } \\
\text { Observação participante. Segundo Queiroz et al (2007, p. 278), é uma } \\
\text { "técnica muito utilizada pelos pesquisadores que adotam a abordagem } \\
\text { qualitativa e consiste na inserção do pesquisador no interior do grupo } \\
\text { observado, [...], interagindo por longos períodos com os sujeitos, } \\
\text { buscando partilhar o seu cotidiano para sentir o que significa estar } \\
\text { naquela situação." }\end{array}$ \\
\hline
\end{tabular}

O objetivo de estudo do presente trabalho é analisar o processo de acompanhamento e controle financeiro informatizado das operações de vendas em uma empresa comercial de material de construção, de pequeno porte, localizada em Minas Gerais, que no presente trabalho será denominada pelo nome fictício Empresa Material, para manter o sigilo da mesma.

A Empresa Material tem 25 anos, possui administração familiar e conta com gerenciamento informatizado para acompanhar e controlar suas atividades. Contudo, a empresa não elabora o Planejamento Orçamentário anual, ou seja, falta um importante 
instrumento de controle de suas operações.

Para apresentação dos resultados do estudo, algumas telas do sistema de informação utilizado pela Empresa Material foram inseridas no trabalho, e ainda apresentadas as opções disponibilizadas aos usuários para controle das operações relacionadas às vendas, desde o cadastro até o recebimento.

Adicionalmente, o trabalho propõe a adoção do planejamento orçamentário de vendas como instrumento de controle, ressaltando a interdependência entre eles. Porém, não pretende estender a discussão sobre o orçamento como um todo, mas abordar especificamente a questão da proposição do Orçamento de Vendas, fundamental para a determinação do nível de atividades da empresa, visando apresentar alternativa adequada para o gerenciamento das operações de vendas. Entende-se, contudo, a importância em se estender a implantação do orçamento às demais peças orçamentárias.

Para melhor visualização das vantagens da implantação do Orçamento de Vendas, proposto pelo presente estudo, foi elaborado um quadro com apresentação de algumas medidas preliminares sugeridas, seguidas dos respectivos resultados e impactos para a Empresa Material.

\section{APRESENTAÇÃO DOS RESULTADOS}

A Empresa Material trabalha com um sistema integrado, um ERP - Enterprise Resource Planning, que é um sistema integrado, que possibilita um fluxo de informações único, contínuo e consistente por toda a empresa, sob uma única base de dados (PADILHA; MARINS, 2004). Assim, o sistema permite que todas as operações da empresa sejam interligadas, favorecendo um melhor gerenciamento das atividades. Especificamente a empresa tem um grande aliado para o acompanhamento da execução e controle financeiro de suas operações vendas.

O processo de gerenciamento de recebíveis da Empresa Material é composto de várias etapas, que são: cadastro, análise de crédito, vendas, acompanhamento das vendas, cobrança e recebimento. Porém, o presente estudo ocupou-se em apresentar as atividades das operações de venda: cadastro de clientes, acompanhamento de vendas e relatórios de acompanhamentos de valores a receber.

A operação de venda da Empresa Material inicia-se com o cadastro dos clientes, e posterior análise de crédito do mesmo no sistema. A seguir, a Figura 1, apresenta uma tela do 
cadastro financeiro de um cliente no sistema.

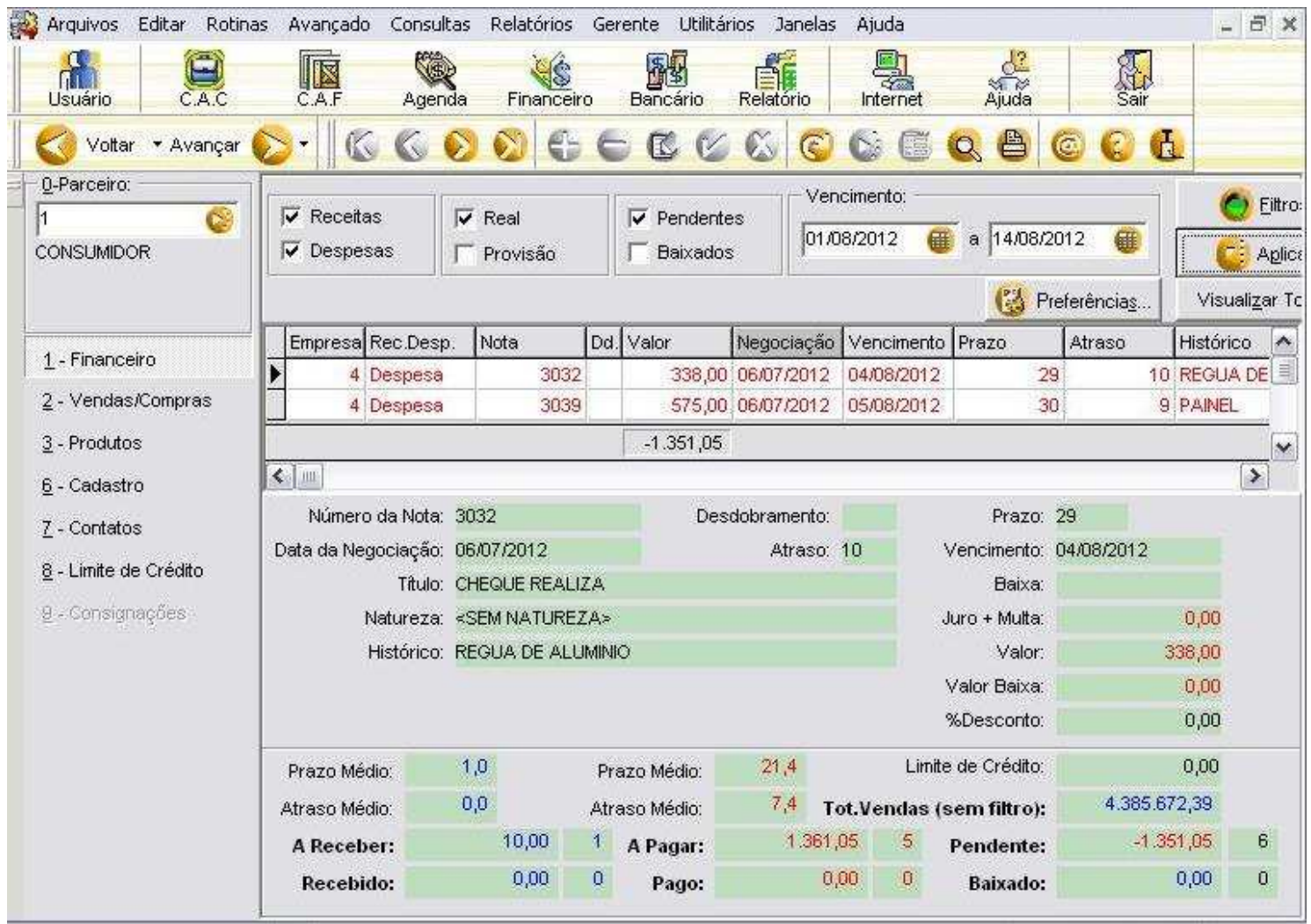

Fonte: dados da pesquisa

Figura 1 - Tela cadastro financeiro de clientes

A Figura 1 apresenta a tela da seção em que é realizada a consulta ao cadastro financeiro do cliente. $\mathrm{Na}$ barra de ferramentas tem-se o menu raiz do sistema, local em que o usuário consegue acessar de forma rápida todas as funções disponíveis. Logo abaixo da barra de ferramentas tem-se os ícones que possibilitam pesquisa e atualização cadastrais. Na parte esquerda da tela, o campo "Parceiro" permite selecionar o cliente pelo nome, CPF (Cadastro de Pessoa Física) / CNPJ (Cadastro Nacional Pessoa Jurídica) ou pelo código gerado no sistema. Logo abaixo do campo "Parceiro" encontra-se um menu com opções que permitem consultas às vendas realizadas, aos produtos adquiridos pelos clientes, ao cadastro geral, aos contatos e limite de crédito definidos para os clientes.

No canto superior direito, no campo "Vencimento" é informada a data do vencimento das vendas realizadas a prazo, que o usuário necessita consultar. Logo abaixo, na parte central da tela, o resultado da pesquisa apresenta o número da nota, valor do pedido, data de negociação, prazo concedido ao cliente, dias de atraso e o histórico dos produtos vendidos por nota. Na parte inferior da tela, é possível consultar o total de valores "A pagar" e 
"Pago" dos clientes, a quantidade de dias de prazo concedidos, e desses a média de dias de atrasos no pagamento, através dos campos "Prazo Médio" e "Atraso Médio".

A partir dos dados apresentados, análises do perfil de compra do cliente podem ser realizadas, verificando se o mesmo realiza compras com frequência, os valores comprados, e no caso de compra a prazo, se os pagamentos são realizados dentro ou fora do prazo. Assim, diante das informações apresentadas pela tela de cadastro financeiro de clientes é possível constatar a relevância do processo de cadastro informatizado para a empresa.

A próxima etapa do processo de gerenciamento informatizado do acompanhamento e controle financeiro das operações de venda seria a análise de crédito dos clientes, porém não será abordado pelo presente trabalho.

A Figura 2 apresenta a tela de consulta de vendas realizadas aos clientes. A tela de consulta de vendas realizadas (Figura 2), assim como a Figura 1, também apresenta a barra de ferramentas, que facilita a utilização das outras funções do sistema pelos usuários. O menu, do lado esquerdo, direciona o usuário conforme seu interesse em consultar vendas realizadas, produtos adquiridos pelos clientes, o cadastro geral, contatos e limite de crédito do cliente, após selecionar o cliente no campo "Parceiro". Na parte superior direita, informa-se o período de negociação da venda que se pretende consultar e, logo abaixo, é possível parametrizar filtros de pesquisa no campo "Filtros" de todas as vendas realizadas aos clientes, por data e valor da venda, tipo de negociação e nome do vendedor. 


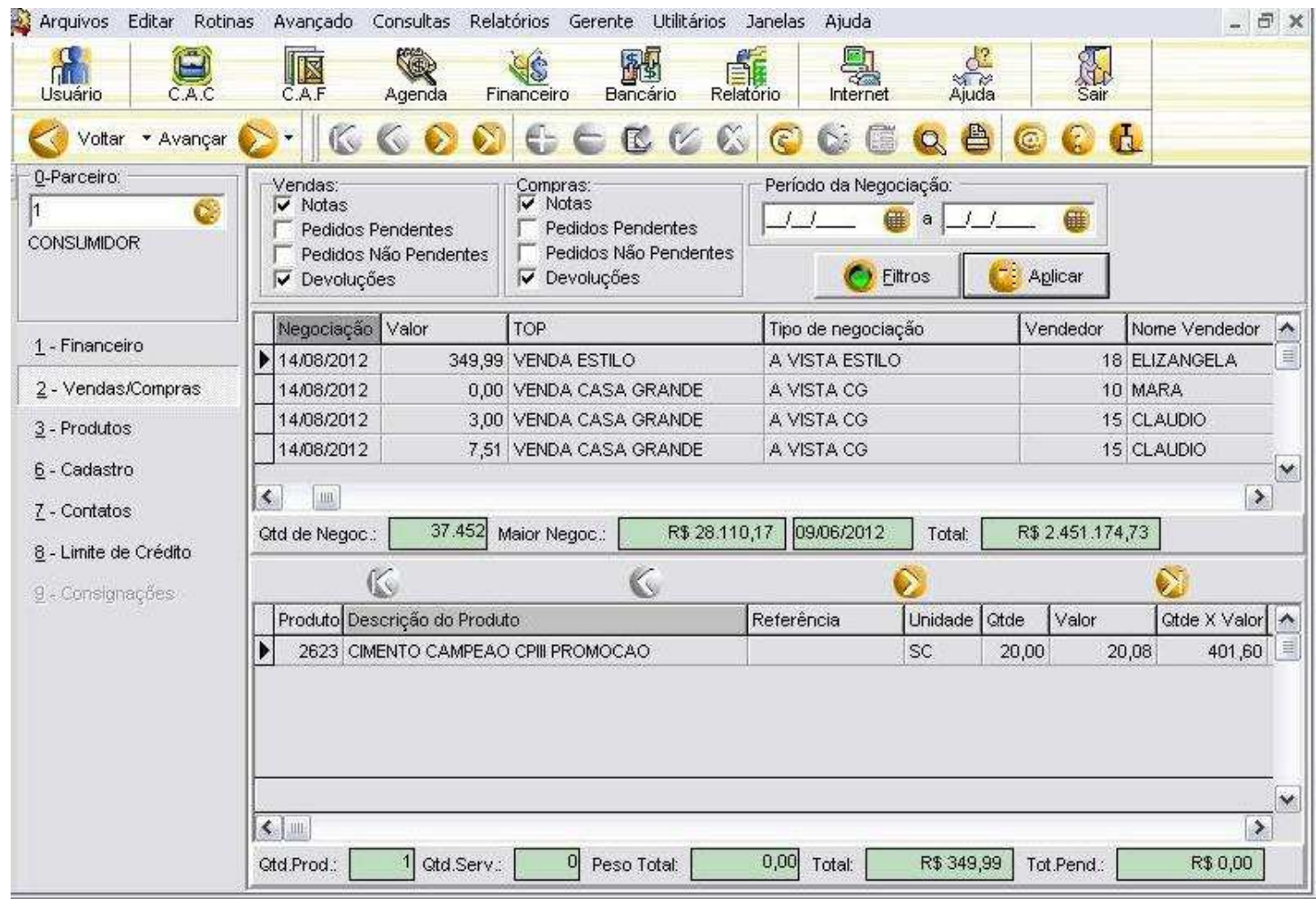

Fonte: dados da pesquisa

Figura 2 - Tela consulta de vendas

Ao selecionar no centro da tela (Figura 2), a negociação que o usuário pretende consultar, é apresentada a descrição do item vendido, a quantidade vendida e os seus respectivos valores. Logo abaixo, no campo "Maior Negoc" tem-se o valor e data da maior venda realizada para o cliente, seguida do campo "Total" com a apresentação do valor total de vendas realizadas para o mesmo.

A importância do sistema de informação para consulta de vendas realizadas está no fato dele possibilitar diversas alternativas de análises e respostas a alguns frequentes questionamentos quanto ao perfil dos clientes, além da análise de desempenho de cada vendedor em relação às vendas realizadas. Alguns dos questionamentos mais comuns, são:

- Quais são os principais produtos adquiridos pelos clientes?

- Qual é a forma de pagamento utilizada com maior frequência?

- Qual é o valor da maior venda realizada ao cliente?

- Qual é o valor total das vendas realizadas ao cliente na empresa?

A próxima etapa considerada pelo presente trabalho é o acompanhamento através de relatórios de controle financeiro de recebíveis. "Depois de efetuadas as devidas análises para a 
liberação de crédito, o próximo passo da empresa é monitorar o desempenho do cliente, verificando se os pagamentos estão ocorrendo conforme acordado, ou se estão ocorrendo atrasos e inadimplências" (LOBATO; SILVA; RIBEIRO, 2009, p. 19).

A seguir, na Figura 3, tem-se a tela do relatório de valores a receber.

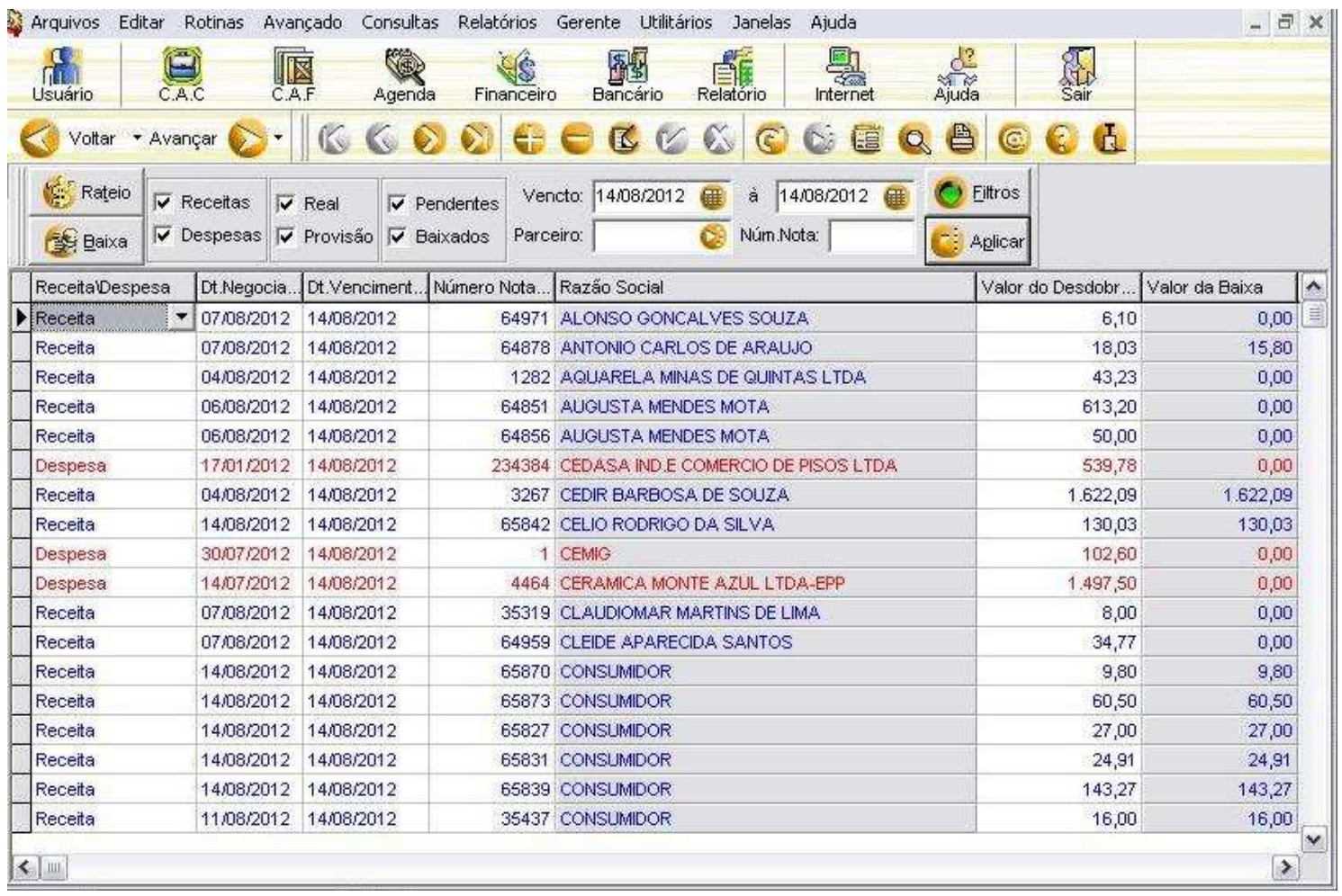

Fonte: dados da pesquisa

Figura 3 - Tela relatórios

$\mathrm{Na}$ tela apresentada (Figura 3), é possível solicitar a impressão de relatórios referentes aos valores a receber da empresa. Assim como nas duas telas anteriores (Figura $1 \mathrm{e}$ Figura 2), a Figura 3 também apresenta a barra de ferramentas, que facilita a utilização das outras funções do sistema pelos usuários.

Nessa seção do sistema (Figura 3), na parte superior, os campos "Pendentes", "Baixados", "Vencto", "Parceiro" e "Núm. Nota", facilitam a localização das vendas realizadas. O campo "Filtros", localizado em frente, permite parametrizações mais avançadas, como por exemplo, busca por valores, data de negociação e data e valor de baixa. Na parte inferior da tela, são apresentados os resultados da busca realizada que permite ao usuário escolher qual ou quais operações de venda deseja visualizar, e contém informações como data de negociação, vencimento, número da nota, nome do cliente, valor da venda e valor da baixa, que podem ser posicionados no relatório de acordo com a ordem que melhor atender às 
necessidades do usuário.

É notória a importância da emissão de relatórios para o gerenciamento de quaisquer operações da empresa. Crepaldi (1998) menciona que as finanças usam informações contábeis para tomar decisões relativas à receita e ao uso de fundos para atingir os objetivos da empresa, e a contabilidade financeira trabalha com informações financeiras úteis para se tomar as melhores decisões relativas ao futuro. Considerando-se a grande aplicabilidade do relatório gerencial para o acompanhamento da execução e controle de quaisquer atividades da empresa, destaca-se especificamente no presente estudo a importância dos relatórios referentes ao controle dos valores a receber.

A Empresa Material tem o instrumento adequado para manter o controle de todos os recebimentos vencidos e a vencer, para dar suporte ao processo de tomada de decisão quanto a sua política de concessão de crédito, conta com gerenciamento informatizado para acompanhar e controlar as atividades financeiras relacionadas às operações de vendas aos seus clientes, desde a análise cadastral até a gestão de recebíveis.

Contudo, identificou-se que a empresa não elabora o Planejamento Orçamentário anual, tão importante instrumento de controle, e consequentemente, não adota o Orçamento de Vendas para nortear as suas atividades. Frezatti (2008) reforça que quem não planeja não pode afirmar que controla, já que não consegue indicar onde quer chegar. Cabe ressaltar ainda que os controles precisam ser parametrizados com base em previsões e estimativas previamente estabelecidas na etapa do planejamento, para dar real sentido ao controle. Considerando-se por essa visão, constata-se que decidir antecipadamente constitui-se em controlar o próprio futuro (FREZATTI, 2008).

Com base nisso, o presente trabalho propõe a adoção do planejamento orçamentário, inicialmente "de vendas", uma vez que a Empresa Material conta com instrumento (Sistema de Informação) favorável de controles preliminares (cadastro) da operação de vendas (Figura 1), consulta às vendas efetuadas (Figura 2) e relatório de contas a receber (Figura 3). Entendese, por outro lado, a importância em se estender a implantação da proposta às demais peças orçamentárias não previstas no presente estudo.

Logicamente, a elaboração do Orçamento de Vendas a Empresa deve identificar, entre as técnicas de previsão de vendas, qual a que melhor se enquadra à sua realidade, e identificar as vantagens e desvantagens de cada uma, de acordo com as características da própria empresa, dos produtos, das informações e, principalmente, dos recursos disponíveis (SANVICENTE; SANTOS, 2000). Ressalta-se que não constitui objetivo do presente estudo 
a identificação do melhor método de previsão de vendas, do tipo de orçamento a ser implementado e nem a apresentação de uma proposta para a implantação do Orçamento de Vendas, decisão que irá depender dos gestores da empresa.

Mediante a proposta de adoção do Orçamento de Vendas, o estudo sugere algumas medidas preliminares a serem implementadas, seguidas dos respectivos resultados e impactos para a Empresa Material (Quadro 2).

\begin{tabular}{|c|c|c|}
\hline \multicolumn{3}{|c|}{ 1. Quanto ao Faturamento } \\
\hline \multicolumn{2}{|l|}{ Medidas a serem implementadas } & Resultados e Impactos \\
\hline \multicolumn{2}{|c|}{$\begin{array}{l}\text { - Estudar previsão de preços; } \\
\text { - Rever os preços praticados; } \\
\text { - Acompanhar as vendas e identificar os } \\
\text { produtos mais vendidos; } \\
\text { - Avaliar o processo de política e } \\
\text { concessão de crédito; } \\
\text { - Conhecer a rentabilidade de cada } \\
\text { produto. }\end{array}$} & 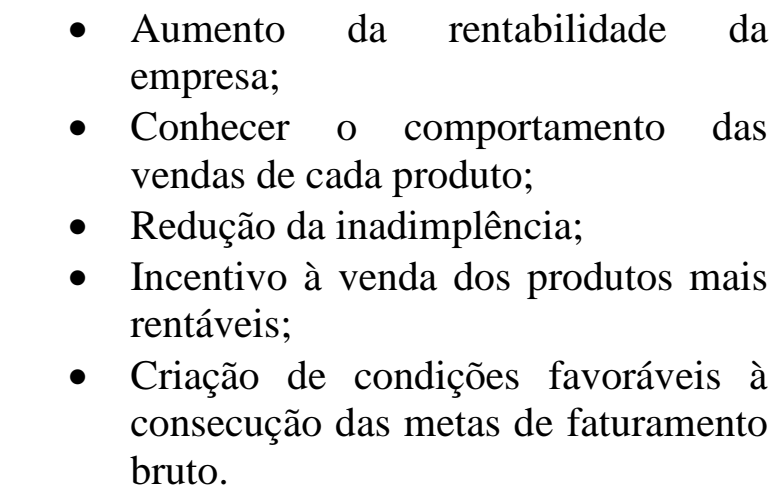 \\
\hline \multicolumn{3}{|c|}{ 2. Quanto ao Controle dos estoques } \\
\hline Medidas a serem implementadas & \multicolumn{2}{|r|}{ Resultados e Impactos } \\
\hline $\begin{array}{l}\text { - Acompanhar os volumes } \\
\text { vendidos; } \\
\text { - Prever as necessidades de } \\
\text { aquisição de estoques para } \\
\text { vendas. }\end{array}$ & & $\begin{array}{l}\text { Aquisição de estoques nos níveis } \\
\text { necessários; } \\
\text { Redução de investimentos desnecessários } \\
\text { em estoque. }\end{array}$ \\
\hline \multicolumn{3}{|c|}{ 3. Quanto ao desempenho da área de vendas } \\
\hline Medidas a serem implementadas & & Resultados e Impac \\
\hline $\begin{array}{l}\text { - Aumentar o controle da atuação } \\
\text { dos vendedores; } \\
\text { - Estabelecer metas de vendas } \\
\text { com base nas vendas anuais; } \\
\text { - Distribuir bônus e premiações } \\
\text { para os vendedores com } \\
\text { melhores performances de } \\
\text { vendas. }\end{array}$ & & $\begin{array}{l}\text { Melhoria do desempenho dos vendedores } \\
\text { da empresa; } \\
\text { Melhoria do controle das operações de } \\
\text { vendas; } \\
\text { Elevação dos esforços de vendas para o } \\
\text { alcance das metas previstas. }\end{array}$ \\
\hline
\end{tabular}

Fonte: elaborado pelas autoras.

Quadro 2 - Sugestão de medidas a serem implementadas

Para a implantação do Orçamento de Vendas, a Empresa Material terá que implantar o módulo orçamentário no sistema, do contrário terá que desenvolver o Orçamento de Vendas em planilhas eletrônicas, e a cada período acompanhar a execução orçamentária das vendas, 
manualmente. É importante ressaltar que a implantação de um módulo orçamentário no sistema demandará a elaboração de um projeto de investimento, que de acordo com Woiler e Matias (1996, p. 27), "é entendido como sendo um modelo que, incorporando informações qualitativas e quantitativas, procura simular a decisão de investir e suas implicações."

Espera-se que a implantação do módulo orçamentário, e consequente elaboração do Orçamento de Vendas, somado ao acompanhamento e controle da sua execução, traga inúmeros benefícios para a Empresa Material. Acredita-se que com a proposta será possível também à empresa realizar o acompanhamento das vendas por vendedor, bem como avaliar o desempenho e o alcance das metas orçamentárias de venda por cada um dos mesmos. Maximiano (1997, p. 88) cita como indicadores de sucesso de um projeto, entre outros, os seguintes:

- Inovação tecnológica: o atingimento de resultado técnico relevante;

- Qualidade técnica: atingimento dos padrões técnicos especificados;

- Custos e prazos: atendimento das estimativas de tempo e recursos financeiros.

Outro ponto a ser considerado é quanto ao treinamento dos funcionários envolvidos no processo orçamentário, além de um forte trabalho no sentido de mudança da cultura e conscientização dos responsáveis pelo processo. Frezatti (2008) atenta que a capacitação técnica diz respeito ao entendimento da organização em termos do controle orçamentário, ressalta também outros aspectos do lado humano do controle, fundamentais para a adequada adoção e utilização dos instrumentos de planejamento e controle.

Por fim, apresenta-se uma iniciativa do Sebrae: Com o objetivo de ampliar a competitividade dos empreendimentos no mercado das micro e pequenas empresas, o Sebrae deu início ao projeto Agente Local de Inovação (ALI) em alguns estados do Brasil. O projeto tem o objetivo de difundir a cultura da inovação nas micro e pequenas empresas, estimular a adoção de novas práticas e tecnologias em gestão, processos, produtos e serviços (SEBRAE, 2012). Espera-se que o presente estudo estimule a adoção das referidas práticas pela empresa de pequeno porte estudada e por demais empresas do país. 


\section{CONSIDERAÇÕES FINAIS}

O presente estudo analisou o processo de acompanhamento e controle financeiro informatizado das operações de vendas em uma empresa comercial de material de construção. Adicionalmente, propôs a adoção do planejamento orçamentário de vendas como instrumento de gestão. Para tanto, foi desenvolvido um estudo de caso em uma empresa de material de construção de pequeno porte localizada em Minas Gerais.

A partir dos fundamentos teóricos sobre planejamento e controle, orçamento de vendas, gestão de recebíveis e sistema de informação e da apresentação dos aspectos metodológicos adotados para o desenvolvimento do trabalho procedeu-se a descrição do estudo de caso.

Observou-se que a empresa objeto do presente estudo conta com gerenciamento informatizado para acompanhar e controlar todas as atividades financeiras relacionadas às operações de vendas aos seus clientes, desde a análise cadastral até a gestão de recebíveis. O estudo apresentou os benefícios do processo de acompanhamento e controle financeiro informatizado das operações de vendas por meio da apresentação de telas do Sistema de Informação utilizado pela empresa e ainda comentou sobre as opções disponibilizadas aos usuários para o referido processo. Foram constatados os grandes benefícios do Sistema de Informação para o gerenciamento das operações de vendas da empresa estudada.

Identificou-se que a empresa em questão não elabora o Planejamento Orçamentário anual, tão importante instrumento de gestão, e consequentemente, não conta com o Orçamento de Vendas para nortear as suas operações. Com base nisso, propôs-se a adoção do Orçamento de Vendas que poderá trazer inúmeras vantagens para a empresa objeto do presente estudo. Para melhor visualização das vantagens da implantação do Orçamento de Vendas foi elaborado um quadro com a apresentação de algumas medidas preliminares sugeridas, seguidas dos respectivos resultados e impactos para a empresa.

Ressalta-se que o trabalho propôs a adoção do planejamento orçamentário como instrumento de controle, enfatizando a interdependência entre eles. O Orçamento de Vendas apresentou-se como alternativa adequada para subsidiar o processo de acompanhamento da execução e controle das operações de vendas e para o processo de tomada de decisão da empresa. Porém, não estendeu a discussão sobre o orçamento global, mas abordou especificamente a proposta de adoção do Orçamento de Vendas, fundamental para a determinação do nível de atividades da empresa. Porém, o estudo deixa clara a importância 
em se estender a implantação da proposta às demais peças orçamentárias.

\section{REFERÊNCIAS}

ASSAF NETO, A.; SILVA, C. A. T. Administração do capital de giro. 3. ed. São Paulo: Atlas, 2002.

ASSAF NETO, A. Finanças corporativas e valor. 3. ed. São Paulo: Atlas, 2008.

ATKINSON, A. A.; BANKER, R. D.; KAPLAN, R. S.; YOUNG, M. Contabilidade gerencial. São Paulo: Atlas, 2000.

BELLÓRIO, M.; RIBEIRO, K. C. S.; ROGERS, P. A Implantação de um sistema de gestão de crédito (SGC) em uma empresa do setor agroindustrial. Anais do V Congresso Brasileiro de Administração Rural (ABAR), Campinas, SP, Brasil, 2005.

BORNIA, A. C.; LUNKES, R. J. Uma Contribuição à Melhoria do Processo Orçamentário. Contabilidade Vista \& Revista, v. 18, n. 4, p. 37-59, 2007.

CAMARGO, M. E.; GIRALDI, G. Previsão de vendas: Um estudo de caso em uma empresa do setor têxtil. Anais do XIV Simpósio de Engenharia de Produção, Bauru, SP, Brasil, 2007.

CATELLI, A. Controladoria: Uma abordagem da gestão econômica - GECON. São Paulo: Atlas, 2001.

CAVALCANTE, E. M. C. O planejamento de micro e pequenas empresas comerciais por meio da atuação da controladoria. Monografia, Faculdade Lourenço Filho, Fortaleza, CE, Brasil, 2010.

CREPALDI, S. A. Contabilidade gerencial: Teoria e prática. São Paulo: Atlas, 1998.

FREZATTI, F. Orçamento empresarial: Planejamento e controle gerencial. São Paulo: Atlas, 2008.

FREZATTI, F., RELVAS, T. R. S., JUNQUEIRA, E. R.; NASCIMENTO, A. R. Análise crítica da contabilidade gerencial no Brasil sob a ótica dos professores de pós-graduação stricto sensu da área. Anais do $\mathbf{8}^{\mathbf{0}}$ Congresso USP de Controladoria e Contabilidade, São Paulo, SP, Brasil, 2008.

FURRIER, M. T.; SERRALVO, F. A. Previsão de vendas e planejamento da produção: Uma abordagem processual em empresas de manufatura. Anais do XV Simpósio de Engenharia de Produção - SIMPEP, Bauru, SP, Brasil, 2008.

GIL, A. C. Como elaborar projetos de pesquisa. 4. ed. São Paulo: Atlas, 2002. 
GUERREIRO, R. Um modelo de sistema de informação contábil para mensuração do desempenho econômico das atividades empresariais. Caderno de Estudos - FIPECAFI, n.4, p. 1-19, 1992.

HOJI, M. Administração financeira e orçamentária: matemática financeira aplicada, estratégias financeiras e orçamento empresarial. 6. ed. São Paulo: Atlas, 2007.

HORNGREN, C. T. Contabilidade de custos. 9. ed. Rio de Janeiro: LTC., 2000.

HORNGREN, C. T.; SUNDEM, G. L.; STRATTON, W. Contabilidade gerencial. 12. ed. São Paulo: Prentice Hall, 2004.

JONES, G. D. C.; NOGUEIRA, L. R. T.; CURI, M. A., GALlON, A. V.; NUINTIN, A. A. Aplicação de um modelo de gestão do orçamento de vendas: Um estudo de caso em uma indústria mineira. Anais do XVII Simpósio de Engenharia de Produção, Bauru, SP, Brasil, 2010.

JONES, G. D. C.; RIBEIRO, K. C.; ROGERS, P. Proposta de um modelo-síntese para planejamento e controle orçamentário: Estudo de caso em uma empresa industrial. Anais do XIV Congresso Brasileiro de Custos, João Pessoa, PB, Brasil, 2007.

LAS CASAS, A. L. Administração de vendas. 7. ed. São Paulo: Atlas, 2004.

LAUDON, K. C.; LAUDON, J. P. Sistemas de informação gerenciais: Administrando a empresa digital. 5. ed. São Paulo: Prentice Hall, 2004.

LEITE, R. M.; CHEROBIM, A. P. M. S.; SILVA, H. F. N.; BUFREM, L. S. Orçamento empresarial: Levantamento da produção científica do período de 1995 a 2006. Revista Contabilidade e Finanças, USP, v. 19, n. 47, p. 56 - 72, 2008.

LEMES JR., A. B.; RIGO, C. M.; CHEROBIM, A. P. M. S. Administração Financeira: Princípios fundamentos e práticas brasileiras. 5. ed. Rio de Janeiro: Elsevier, 2002.

LOBATO, F. T. R.; SILVA, A. P.; RIBEIRO, K. C. S. O impacto da estratégia de crédito na liquidez e rentabilidade: Uma análise das lojas de departamentos do setor de comércio varejista. Revista Contemporânea de Contabilidade, ano 6, v.1, n. 12, p. 11-34, 2009.

LUFT, J.; SHIELDS, M. Mapping management accounting graphics and guidelines, accounting. Organization and society. 28, pp. 169-249, 2003.

MACHADO, N. Sistema de informação de custo: Diretrizes para a integração ao orçamento público e à contabilidade governamental. Tese de doutorado, Faculdade de Economia, Administração e Contabilidade da Universidade de São Paulo, São Paulo, SP, Brasil, 2002.

MARCONI, M. A.; LAKATOS, E. M. Fundamentos de metodologia científica. 6. ed. São Paulo: Atlas, 2006. 
MAXIMIANO, A. C. A. Administração de projetos: transformando idéias em resultados. São Paulo: Atlas, 1997.

MEDEIROS, K. M.; BRITO, F. I.; ARAUJO, A. O. Gestão de crédito e cobrança: análises dos resultados da terceirização em uma financeira. Anais do V Congresso USP Iniciação Cientifica em Contabilidade, São Paulo, SP, Brasil, 2008.

MENTZER, J. T.; BIENSTOCK, C. C. Sales forecasting management. California: Sage publications, 1998.

MIGLIATO, A. L. T. Planejamento estratégico situacional aplicado à pequena empresa: Estudo comparativo de casos em empresas do setor de serviços (hoteleiro) da região de Brotas - SP. Dissertação de mestrado, Escola de Engenharia de São Carlos, Universidade de São Paulo, São Carlos, SP, Brasil, 2004.

MOREIRA, J. C. Orçamento empresarial: manual de elaboração. São Paulo: Atlas, 2002.

NAKAGAWA, M. Introdução à controladoria: conceitos, sistema, implementação. 1. ed. São Paulo: Atlas, 1993.

O'BRIEN, J. A. Sistemas de informação e as decisões gerenciais na era da Internet. 2. ed. São Paulo: Saraiva, 2004.

PADILHA, T. C. C.; MARINS, F. A. S. Sistemas ERP: características, custos e tendências. Revista Produção, v. 15, n. 1, p. 102-113, 2005.

PADOVEZE, C. L. Sistemas de informação contábeis: fundamentos e análise. 2. ed. São Paulo: Atlas, 2000.

PEREZ JUNIOR, J. H.; PESTANA, A. O.; FRANCO, S. P. C. Controladoria e gestão: teoria e prática. 2. ed. São Paulo: Atlas, 1997.

QUEIROZ, D. T.; VALL, J.; SOUZA, A. M. A.; VIEIRA, N. F. C. Observação participante na pesquisa qualitativa: Conceitos e aplicações na área da saúde. R Enferm UERJ. 2007.

Disponível em: http://www.facenf.uerj.br/v15n2/v15n2a19.pdf. Acesso em: 15 ago. 2015.

RAUPP, F. M.; BEUREN, I. M. Como elaborar trabalhos monográficos em contabilidade. 3. ed. São Paulo: Atlas, 2006.

SANVICENTE, A. Z.; SANTOS, C. C. Orçamento na administração de empresas: planejamento e controle. São Paulo: Atlas, 2000.

SEBRAE. Agentes locais de inovação, 2012. Disponível em:

http://www.sebrae.com.br/sites/PortalSebrae/Programas/Agentes-Locais-deInova\%C3\%A7\%C3\%A30:-receba-o-Sebrae-na-sua-empresa. Acesso em: 30 jan. 2016.

SEBRAE. Sobrevivência das empresas no Brasil: coleção estudos e pesquisa. 2013. Disponível em: 
file:///D:/Sobrevivencia_das_empresas_no_Brasil=2013.pdf. Acesso em: 30 jan. 2016.

SECURATO, J. R. Análise e avaliação do risco - pessoas físicas e jurídicas. São Paulo: Editora Atlas S.A, 2002.

TERENCE, A. C. F. Planejamento estratégico como ferramenta de competitividade na pequena empresa: desenvolvimento e avaliação de um roteiro prático para o processo de elaboração do planejamento. Dissertação de mestrado, Escola de Engenharia de São Carlos, Universidade de São Paulo, São Carlos, SP, Brasil, 2002.

WELSCH, G. A. Orçamento empresarial. 4. ed. São Paulo: Atlas, 1983.

WOILER, S.; MATHIAS, W. F. Projetos: planejamento, elaboração, análise. São Paulo: Atlas, 1996.

YIN, R. K. Estudo de caso: planejamento e métodos. 2. ed. Porto Alegre: Bookman, 2001. 